\title{
The Articulation of Enkinaesthetic Entanglement
}

\author{
Susan A J Stuart \\ University of Glasgow, UK
}

[Forthcoming in: Inscribing the Body, Andreas Ackermann, Matthias Jung \& Michaela
Bauks (eds.), Wiesbaden: Springer VS, 2015/16, pp.19-36]

\begin{abstract}
In this article I present an argument for the necessary co-articulation of meaning within our felt enkinaesthetic engagement with our world. The argument will be developed through a series of stages, the first of which will be an elaboration of the notion of articulation of and through the body. This will be followed by an examination of enkinaesthetic experiential entanglement and the role it plays in rendering our world meaningful and our actions values-realising. At this stage I will begin to extend Husserl's notion of intentional transgression to the enkinaesthetic sphere of lived experience, and in support of this claim I will examine the theoretical and practical work of osteopathic manual listening [Gens \& Roche 2014] and the 'felt sense' in focusing [Gendlin] which makes possible a shift from a somatic articulation to a semantic, and potentially conceptual, one. Throughout, my position will be compatible with Merleau-Ponty's claim that "Whenever I try to understand myself, the whole fabric of the perceptible world comes too, and with it comes the others who are caught in it." [Merleau-Ponty 1964a, p.15].
\end{abstract}

\section{Introduction}

In a similar way to Merleau-Ponty [1962, 1964a, 1964b 1968 \& 1970] my task will be to uncover, one might even say elicit, the sensual layers of pre-theoretical living within our lifeworld or Lebenswelt. Yet I go further than this; my central concern is with the articulation of a world of meaningful experience, created, in part, at least, by a process of prenoetic mutually transgressive affective neuromuscular entanglement; a great deal of the paper will be spent working towards a satisfactory account of what is meant by this mutual transgression. At first blush it will seem paradoxical to use the term 'articulation' in the context of pre-reflective felt experience, for if that experience is pre-reflective, it will be pre-conceptual, non-propositional, non-representational, and, we would imagine, incapable of being articulated in the usual way we conceive of articulation. So, let's begin by making clear what will not be our concern: (i) the more usual uses of 'articulation' to mean the articulation of clear sounds in speech, (ii) or the putting into words of a previously inchoate idea, or (iii) any notion of articulation which is centred on the individual and potentially solipsistic. Whilst the first two are interesting and have been the subject of sustained concern for centuries' worth of the writings of others, the third, I argue elsewhere [Stuart 2012], is specious and, what's more, impossible. Thus, our much more specific concern is with the articulation of meaning through and by the intentionally-saturated activity of the living body in an affective community of other living bodies and things. ${ }^{1}$ It is a richly

\footnotetext{
${ }^{1}$ I have elsewhere, for example, Stuart 2010 \& Stuart 2012, used the categories of 'agential' and 'non-agential', but given Latour's arguments for the action or participation of non-humans ('actants') within rhizomic-networks (see, for example, Latour 2005), I am content to construe the former as intentional, the latter as non-intentional, and both as significant, contributing to the co-articulation of meaning, within a dynamic material-semiotic.
} 
affective, plenisentient community, characterised by the implicit intricacy of a pre-reflective neuromuscular entanglement through which we are the unthinking co-creators, that is, co-articulators of our shared world. ${ }^{2}$ I will argue that this affective co-articulation is made possible by a condition of our own subjectivity, and that this condition is a prenoetic somatosensory intentional transgression of the living dynamic experiencing being of the other. Thus, I will argue, our lived experience is always tempered by the direct spontaneous reception, or passive synthesis, of the experientially entangled living being of the other as they transgress our own experience and we theirs. I will refer to this as the enkinaesthetic community and reciprocity of our affective being with our world - our Mitseinwelt, and it is our folding into, enfolding with, and unfolding from this community which is the co-articulation of our shared meanings.

The most immediate question that arises is what is involved in this process of somatic, semantic and, by no means necessarily, conceptual articulation; so, we will start by an elaboration of the notions of articulation of and through the body, and then, through the articulated and articulating body, we will reach out through our enkinaesthetic experiential entanglement with other living bodies to the role that living, breathing, feeling bodies play in rendering our shared worlds meaningful and our actions values-realising. In doing this I will extend Husserl's notion of intentional transgression to the enkinaesthetic sphere of lived experience, and in support of this claim I will examine the theoretical and practical work of osteopathic manual listening [Gens \& Roche], and the 'felt sense' in focusing [Gendlin 1966, 1992, 1997 \& 2015] which emphasises the possible shift from a somatic articulation to a semantic one. Throughout the whole my position will be compatible with Merleau-Ponty's claim that

Whenever I try to understand myself, the whole fabric of the perceptible world comes too, and with it comes the others who are caught in it. ... For [others] are not fictions with which I might people my desert-offspring of my spirit and forever unactualized possibilities-but my twins or the flesh of my flesh. [Merleau-Ponty 1964, p.15]

Let's start with a skeleton, put some living, breathing, sensing flesh on its bones, and then proceed, by feeling our way towards an articulation of our twins, the flesh of our flesh.

\section{Articulation}

There is a character, Mr Venus, in Charles Dickens' Our Mutual Friend, whose employ is as an articulator of bones, someone who reconstructs the skeleton of animals, including human animals, and who occasionally extends their skills to taxidermy, that is, making the animal appear as though it still has flesh on its bones. Mr Venus, who possesses the amputated leg of his interlocutor, Mr Wegg, exclaims that:

[I]f you was brought here loose in a bag to be articulated, I'd name your smallest bones blindfold equally with your largest, as fast as I could pick 'em out, and I'd sort 'em all, and sort your wertebræ, in a manner that would equally surprise and charm you. [Chp. VII, p.64]

It's a vivid passage, not least because of the ironic suggestion that Mr Wegg would be around to be delighted by Mr Venus's remarkable feats of reassembly when he has re-articulated his bones, but also for the ease and skill with which Mr Venus makes sense of a skeletal world so familiar to his touch, to his vision, to his life-world. Each of the bones, even the smallest, has significance for, that is, has meaning and matters to, Mr Venus. Through his affective acquaintance he would be able to rearticulate and make sense of Mr Wegg's frame, with each of the individual bones articulating where

\footnotetext{
${ }^{2}$ None of this is to imply that there is no cognitive activity going on, there may be, there may not; and nor is it to suggest that there is no linguistic community, there may well be; it is merely to suggest that this is not the concern of this current paper.
} 
they meet, in the microcosm of their intertwinings. A single bone is inarticulate, yet in Mr Venus's hands it has meaning, it is a value-object, and with Mr Venus's intervention and in conjunction with other bones, all value-objects, its complex social meanings are articulated. Their articulation can be described in functional terms as permitting this or that extent of movement, this or that orientation, these or those degrees of freedom, as having single or multiple axes of movement, and as having flat, concave or convex surfaces, but more importantly their articulation is hermeneutic, making sense and giving voice to the individually unintelligible or incoherent. Mr Venus, as an articulator of bones, is a re-creator of worlds of meaning, where the elements act not as isolated individuals free from any impingement on others, and where the sense of affecting change and being affected brings forth, that is, articulates worlds for the multiplicity of unions. Such unions are not simplified dyadic interactions, and not only for Mr Venus. The whole, including Mr Wegg and beyond, is massively polyadic, consisting not just of other living beings and things, but also memories, utterances, and events, past, present and future, all of which matter or have significance for us because they affect us and alter us, and in this universal dialogue we affect and alter them. It is within this affective community and reciprocity we feel our way in a co-articulated values-realising co-constituting dynamics.

Yet, for all this, the world of meaning that Mr Venus re-creates cannot yet be our 'twin' in the way Merleau-Ponty implies. To be our 'twin' Mr Wegg's skeleton must have feeling and sensing flesh on its bones, and this would have to comprise some part of its neurodynamical enkinaesthetic ability to feel the givenness and ownership of its own experience as entwined with the living feeling breathing dynamical being of other living beings and things. Only if this is the case can our 'twin' be affected and altered, can it sense and anticipate, and only if this is the case can it reciprocate in a co-articulation of meaning and value. So let's examine in a little more detail what Merleau-Ponty might mean when he says that others are not fictions, that they are the flesh of my flesh; to do this we'll explore the notion of articulation through the lens of enkinaesthetic theory.

\section{Enkinaesthetic Co-Articulation}

There are three characteristics of enkinaesthetic theory which are crucial for this paper. The first is that there exists between us and other agents a prosody of resonance and fragmentation, in the form of interpersonal felt cadences that are "regulated by emotions of affection and enjoyment, expressed and given meaningful form by rhythms of modulated movement" [Malloch \& Trevarthen 2009, p.2]. The second is that, through our actions and perceptions we inhabit the other's experience, which is to say that there exists an immanent intercorporeality in the prosody of our neuro-muscular entanglement. This notion is similar to Husserl's notion of Paarung, but we will also see that it is profoundly different. And, the third feature arises as an interplay of the first and second, for in that interplay we don't just enact and articulate our own meanings, we also bring forth, that is, articulate others' meaning. So, just as Varela claims about an object, that it is not 'out there' independently, but "arises because of your activity, so, in fact, you and the object are co-emerging, co-arising" [Varela 1999, pp.71-72], I claim that the co-articulation of meaning arises out of our enkinaesthetic co-emerging, co-arising. We'll proceed by examining these aspects in more detail.

Trevarthen observes that "There is an old and frequently rediscovered understanding that we come alive as subjects or persons only in relation with others, by [our] being innately sensitive to their actions toward us"3; I would add, and their being innately - and synchronously - sensitive to our actions towards them, for only with that co-responsiveness can we feel the other as immanent in our own being. Enkinaesthetic theory is a further rediscovery of this understanding, but it is also a development of it, bringing with it a means of drawing together how we articulate our concerns and the concerns of others within the sensitive community and reciprocity of living being, where each action, already characterised by its givenness and a saturated intentionality, engenders affect and that affect engenders action, not just within ourselves but within all life. Thus, it is through our

\footnotetext{
${ }^{3}$ This is from an early draft of a paper sent in personal correspondence. It is worth noting that in that paper Trevarthen refers to Hutcheson 1755, Smith 1759, Buber 1937, Macmurray 1961, and Reddy 2008 who each make this 'rediscovery' from fascinating perspectives.
} 
enkinaesthetic entanglement that we experience the intercorporeal resonances, and the fractures and fragmentation of resonances, with those agents with whom, and those objects with which, we are in a perpetual community of reciprocal relations, within the experiential repertoire of the whole. As Sperry says "The experience of the organism is integrated, organised, and has its meaning in terms of coordinated movement." [Sperry 1939, p.295], but Sperry is too cautious and fails to mention that movement is affectively coordinated with the energic pitches, cadences, and tempos that characterise our polyphonic intertwining with other organisms and things [Stuart \& Thibault 2015].

Communication between similarly motivated and similarly formed subjects, with the same kind of brain and the same rhythms and forms of attending, evidently has evolved by brains taking up and engaging with - or resonating to - the timing, aim, and style of these intentional and sense-directed activities generated in other brains. [Trevarthen 2009, p.12] ${ }^{4}$

Without embracing Trevarthen's emphasis on the brain, I am claiming that this communication is a natural, direct and unmediated apprehension of the other's experience in our own. This is not to say that our experience of the other's experience is from their perspective; that would be absurd. It is to say that when Merleau-Ponty speaks of others as real in our experience, as the flesh of my flesh, he is claiming that the other is "always "already there" [in my experience] before reflection begins' [Merleau-Ponty 1970, p.65], and that it is an always already there as the 'primordial being which is not yet the subject-being nor the object-being' (Merleau-Ponty 1970: 65). In this way, in the day-to-dayness of the community and reciprocity of our affective Mitseinwelt we need neither to develop and implement some conjectural cognitive theory about the mind of the other, nor to perform some curious simulation of what the other might be thinking if we were them, and neither of these is required because we routinely transgress our own bodily boundaries spilling over into, that is, pervading the plenisentient bodily experience of the other, and they ours.

[A]t the same time the other who is to be perceived is himself not a "psyche" closed in on himself, but rather a conduct, a system of behavior that aims at the world, he offers himself to my motor intentions and to that "intentional transgression" (Husserl) by which I animate and pervade him. [Merleau-Ponty 1964b, p.118]

Husserl argues that, through a process of corporeal analogising, by which he means recognising the other as having a body similar to our own, we co-present the other and understand it to be, not simply a body like an object, Körper, but as being an 'ensouled', psychic, or living body, Leib. ${ }^{5}$ Analogising in this way couples ego and alter ego as Paarung, where the other, as psychically distinct from me, is, nevertheless, appresented as Leib. The emphasis for Husserl is on the auditory and visual perception of the other as having a moving, kinaesthetic body like my own, and it is in this observation that an 'intentional transgression' occurs, and I spontaneously appresent the other as another ego, an alter ego. Merleau-Ponty also emphasises the role of visual perception saying:

Husserl said that the perception of others is like a "phenomenon of coupling" (accouplement). The term is anything but a metaphor. In perceiving the other, my body and his are coupled, resulting in a sort of action which pairs them (action à deux). This conduct which I am able only to see, I live somehow from a distance. I make it mine; I recover (reprendre) it or comprehend it. [ibid.]

\footnotetext{
${ }^{4}$ Marvellous examples of this affective coordination are given in Validation Therapy, see: https://vfvalidation . org/web.php?request=index especially the validation breakthrough with Gladys Wilson https://www. youtube. com/watch?v=CrZXz10FcVM

${ }^{5}$ The anomalous counter-factual cases of, for example, antisocial personality disorders, including psychopathy and sociopathy (DSM-5 301.7), of depersonalisation or derealisation disorders (DSM-5 300.6), of Cotard's delusion (DSM-5 297.1), and of Capgras syndrome, reveal our co-presentation of the other as Leib to be the non-anomalous one might say, natural, everyday response to other human beings. All references from DSM-5 2013.
} 
Enkinaesthetic theory takes the intentional transgression further beyond Husserl's and Merleau-Ponty's conceptions, arguing that visual and corporeal analogising plays only a greatly diminished role in our grasp of the intentional arc of the other's current and future action, and that the 'alter' ego that we appresent whilst remaining visually other, is not affectively other; this appresented other is already there in its primordiality. We have no need for analogising the physical body with our own, recognising it as similar, and switching to seeing it as a living being. We are always already within the perpetual felt community and reciprocity of an enkinaesthetic field, where "field" refers to the domain within which a particular condition prevails - in this case a topologically complex, affectively-laden, intentionally-saturated Mitseinwelt of other beings and things. We dwell within our plenisentient intersubjective engagement with other agents, human and non-human, and this dwelling, this entangled enkinaesthetic experience, is a transcendental condition for the prenoetic affect, which makes alter ego identification, co-presentation, co-articulation, and co-action possible. ${ }^{6}$ In these massively polyadic enkinaesthetic intertwinings, the simultaneous experience of our affect on others and their affect on us has an immanence in our being; we are, at one and the same time, both subject and object, and object not just in the gaze of the other, but also in our own sensed reflection in our memory, and in our anticipatory framing of ourselves within horizons of current and future possibilities.

In a phrase redolent of Merleau-Ponty's 'chiasm', Young (1980) uses "ambiguous transcendence" to describe the experiential inseparability of our being, at one and the same time, both subject and object; the dynamics of such a crisscrossing or 'intertwining' of the "touching [subject] and the tangible [object]", are fundamental for the success of living organisms within the enkinaesthetic field. ${ }^{7}$

This can happen only if my hand, while it is felt from within, is also accessible from without, itself tangible, for my other hand, for example, if it takes its place among the things it touches, is in a sense one of them, opens finally upon a tangible being of which it is also a part. Through this crisscrossing within it of the touching and the tangible, its own movements incorporate themselves into the universe they interrogate, are recorded on the same map as it ... [Merleau-Ponty, 1968, p.133]

There is here no problem of the alter ego because it is not I who sees, not he who sees, because an anonymous visibility inhabits both of us, a vision in general, in virtue of that primordial property that belongs to the flesh, being here and now, of radiating everywhere and forever, being an individual, of being also a dimension and a universal. [ibid., p.142]

It is in this way, through the everywhere and forever radiation of resonances and fragmentations within our enkinaesthetic chiasm, that we bring forth, that is, co-articulate our, that is, collectively 'our', world. And, in this way, our 'own' world can never be brought forth or articulated, without the worlds of all others being brought forth or being articulated too; they are always already within our own articulation, immanent and never fully transcendent. Thus we are, at one and the same time, prenoetically a universal non-individuated being, and noetically (and visually) individuated.

All that I've said here is consistent with the direct perception theory ${ }^{8}$ [Chemero 2006 \& Gallagher 2008] proposed as an alternative to theory-theory [Carruthers \& Smith 1996] and simulation-theory [Davies \& Stone 1995] as the means by which we understand what is in another's mind. There is something so remarkably cumbersome about having to first establish a theory, in some third-person

\footnotetext{
${ }^{6}$ There is no opportunity in this current paper to do justice to the claim that there exist, and indeed that there must exist, intra- and inter-species enkinaesthetic resonances and fragmentations. In this regard I wholeheartedly commend to the reader Chapter 3, "Affect Attunement, Discourse Ethics Across Species", of Willett's Interspecies Ethics.

${ }^{7}$ An alternative, not a counter-, example from nature might be an animal which can simultaneously be both predator and prey. Weasels prey on smaller mammals like mice and voles, but they are also prey for larger predators like foxes and owls; and fish are nearly all piscivorous which means that they eat fish but they are also likely to be eaten by larger fish. In both these cases weasel and fish are likely to be simultaneously the subject of their experience and aware that they might also be the object of the other's experience; they are both the touching and the tangible.

${ }^{8}$ That enkinaesthetic entanglement is consistent with direct perception theory does not imply agreement with or acceptance of that theory. Direct perception is fine as far as it goes, but it doesn't go far enough. Enkinaesthesia offers immanence, experiential transgression, extended body theory, and co-articulation, all of which take direct perception into new territory.
} 
scientific manner, about what another may be thinking, or having to place myself rather awkwardly and time-consumingly in the other's 'shoes', so that I can have a first-person experience of the world from 'their' perspective, that makes one wonder why these theories have remained credible for so long. I am not here denying that there are occasions when the situation is massively complicated and I have to judge whether or not I am, for example, being deceived by a smile or humoured by an agreement, but in general this kind of judgement is made post hoc through some reflective analysis; however, crucially, the felt sense we have of doubting the sincerity of an interaction relies on our prenoetic openness to the radiating resonances and fragmentations within our enkinaesthetic chiasm. This too is consistent with Gibson's ecological approach to perceptual experience, the first tenet of which is that perception is direct and not for adding information to sensations; the second is that perception is for action guidance, not information gaining; and the third is that perception is of affordances, the action possibilities within a perceptual horizon. Within this horizon, which is, first and foremost, an enkinaesthetic, intentionally-saturated affective horizon "organism and environment enfold into each other and unfold from one another in the fundamental circularity [the enkinaesthetic community and reciprocity of co-articulation] that is life itself". ${ }^{9}$ [Varela, Rosch, \& Thompson 1991, p.217]

Gendlin's process model [1966, 1992, 1997, \& 2015] provides a means of elaborating this experiential enfolding and unfolding within what he refers to as the implicit intricacy of the organism's bodyenvironment felt sense. I will provide a short summary of Gendlin's work ${ }^{10}$ and then offer a practical extension of it through the technique of osteopathic manual listening [Sutherland; Gens \& Roche 2014]. In this work we have an example of the naturally occurring co-articulation of meaning within the spontaneous enkinaesthetic appresentation of the other's experience in mine, in my experience in the other's.

\section{The Felt Sense in Focusing and Osteopathic Manual Listening}

The 'implicit' has to be felt in the body, but it is not only inside the body. Rather, it consists of body-environment interaction. "Interaction" comes first. Interaction has always already happened, even when we think about a separate environment and a separate body. [Gendlin 2015] $]^{11}$

One way in which we might begin to think about the implicit is as the givenness immanent in our experience. At first glance, this might seem sufficient, but it has echoes of individuation, as though it were somehow possible to separate the givenness of the individual's experience from its experiential situatedness and the community and reciprocity of our being with other living bodies and things. And, it isn't just an 'implicit', it is an "implicit intricacy", and an "implicit interactional bodily intricacy" which characterises the proto-modal relationships of organisms in the practical everydayness of their lived being. In this way we might develop our understanding along enkinaesthetic lines, so that the "implicit intricacy" which is always already there too is our prenoetic enkinaesthetic experiential entanglement.

There is an implicit interactional bodily intricacy that is first - and still with us now. It is not the body of perception that is elaborated by language, rather it is the body of interactional living in its environment. ... We sense our bodies not as elaborated perceptions but as the body sense of our situations, the interactional whole-body by which we orient and know what we are doing. [Gendlin 1992, p.352]

\footnotetext{
${ }^{9}$ Bracketed phrase my addition.

${ }^{10}$ For a detailed account of the Process Model start here: http://www. focusing.org/process.html

${ }^{11}$ We might say that interaction is primary, but it would be no more true for Gendlin's model than it would be true to say it of relation in Leibniz's monadology [Leibniz 1991]; the existence of interaction or relation (respectively) presupposes a multiplicity of entities: bodies, monads, consciousnesses, depending on the ontological commitments of your system. What each model shares or, at least seems to share, is the implicit intricacy with which all things are interwoven. In each it is through consciousness, in each it is relational, in Gendlin's it is also interactional.
} 
Gendlin's "Implicit intricacy" permeates the enkinaesthetic field, folding into, enfolding with, and unfolding from all things within a vast polyadic affective living landscape of articulating and coarticulating microcosmic intertwinings. Conceived thus, living being, Leib, transcends individual bodies and agents within this intricate enkinaesthetic web. As Gendlin says: "nature is an implicit intricacy" [Gendlin 1997, p.347], implying, I will add, but I do not anticipate that Gendlin would disagree, the co-articulation of meaning within a values-realising non-individuated being. This dynamic Gendlin refers to as a "situational understanding", a kind of animal somatic grasp, and it has an ontological and experiential primacy to the "felt sense" that arises and pervades the co-activity or co-articulation of the organism-environment.

If an animal hears a noise, many situations and behaviors will be implicit in its sense of the noise, places to run to, types of predators, careful steps, soundless moves, turning to fight, many whole sequences of behavior. Meanwhile the animal stands still, just listening. What it will do is not determined. Surely it won't do all the implicit sequences - perhaps not even one of just these but some subtler response ... [Gendlin 1997, Chp. II, p. 7]

All living being in its implicit intricacy exists in this way within an enkinaesthetic field of affective enquiry and action. The implicit intricacy of "felt sensing" in its "situational understanding" is the articulation and co-articulation of non-propositional, pre-reflective, pre-conceptual, plenisentient interpretation, anticipation, and communication; all of which takes place within a horizon of action possibilities and comes already laden with the implicit non-propositional questions "how is my world now?", "how is it ... becoming?". The plenisentient responses to these questions pervade the agent and perpetuate a continuously unfolding fresh horizon of action possibilities. It is this which constitutes the 'knowing' referred to by Gendlin, a 'knowing' which occurs in natural agents through an enkinaesthetic affective enfolding which enables the balance and counter-balance, the attunement and co-ordination of whole-body action through mutual reciprocal adaptation.

A felt sense of this kind cannot arise through our thinking ourselves into directing our attention towards an already existing object, as though somehow we are naturally cognitively and connatively separable from them, perceiving them in a successive order and even through distinct individuated senses; to do this is to immediately think ourselves out of an enkinaesthetic co-articulation of meaning, out into the alien world of propositional attitudes and body-environment-independent minds. For a felt sense we must proceed 'feelingly', [Gloucester in King Lear, Act 4, Scene VI] for only then can we articulate a somatic sense of our situation with its openness to action possibilities, and only then can we hope to experience a "felt shift" to a more distinctive semantic articulation.

"Thinking with the implicit" is a means of producing a felt sense or somatic articulation of something that possesses a semantics but which may not yet have words. "As it forms, the "feel" understands itself, so to speak."12 [Gendlin 1997, p.216] The practice of focusing is characterised by enquiry and action, but not necessarily dynamic physical action in the form of movement of the body or limbs; rather it is an attempt to render articulable that which is felt, possibly only inchoately. Focusing is an act of values-realising in seeking though not striving, waiting without the intrusion of impatience or irritation, and an openness to letting a feeling come, and brought with it is a bodily sense of the fit or value of the feeling; in this way, in the community and reciprocity of the enquiry and anticipation, the inchoate begins to take shape. Gendlin says it has a feeling of "rightness or wrongness" [ibid. p.219], but in using any of these terms, 'fit', 'value', "rightness or wrongness" it must also be remembered that their aptness is not at the level of cognitive judgement, but at the level of how they sit within the body. We might think of finding the fit as akin, in some way, to the "a ha" moment that comes when we think "Now I understand.", "Now I know how to go on.” [Wittgenstein 1958, ฯ323], except that the accompaniment to the implicit fit is not a proposition but a prenoetic feeling or body-environment grasp. "A Felt Sense is a distinctly felt object which may now form and come as a bodily-felt "this""

\footnotetext{
12 "So to speak" is such an odd metaphor to use in this context where the central concern is with prenoetic somatic affection and its felt semantic articulation, and not with conceptualisation, judgement and verbalisation. But the phrase is in fairly common use to mean that the words, "the "feel" understands itself", are being used in a non-standard way.
} 
[Gendlin 2015, fn 5], where 'this' has a growing clarity as a referent with an unfolding sense. We might refer to this unfolding sense as a process of interoception or intrasubjective enquiry, but that would be to fail to recognise and acknowledge the implicit intricacy of the enkinaesthetic bodyenvironment as a condition for the articulation of meaning within an organism's horizons of current and future possibilities.

We will now examine the practice of osteopathic manual listening where we can find evidence of just such an unfolding sense, with its shift from a somatic to a semantic bodily-felt 'this' ${ }^{13}$ In addition, because the technique provides an express articulation of enkinaesthetic entanglement, we have a practical corroboration of the co-articulation of a bodily-felt 'this' which is immanent in our enkinaesthetic intentional transgression of and intertwining within the other's experience and in theirs within ours. ${ }^{14}$

Just as with traditional osteopathy, osteopathic listening is a practice which uses the hands, but unlike traditional osteopathy the hands are not used to manipulate the patient's body; instead the therapist's hands are the focal point of a synaesthetic listening-feeling process, the gentle touch - and even non-touch - of palpation, listening for rhythms and arhythms. Just as in focusing, there is, in the listening process, a seeking without striving, a waiting without impatience, and an openness to what presents itself, all of which can occur, in this non-traditional osteopathic method, without needing to be in constant tactile contact with the patient's body, and even without touching it directly at all. It is the non-necessity for touch which makes this form of osteopathic listening particularly intriguing, and especially because of its appreciation for the routine enkinaesthetic transgression of our bodily boundaries in which we pervade the plenisentient bodily experience of the other. In other words, osteopathic manual listening embraces the ambiguous transcendence of the everydayness of our folding into, enfolding with, and unfolding from the other within the processual co-articulation of our shared meanings.

The defining characteristic of this listening process is that it essentially derives from the osteopath's ability to sense the inner space in which organic life develops - in other words, to sense this organic life itself, even though we are raised to believe that such a perception is impossible.

The common view is that, without using a scalpel, it is as impossible for us to have a knowledge of the interior life inside a living organism enveloped in skin as it is for us to see through a wall. [Gens \& Roche 2014, p.2]

The view that this perception is impossible is based on all manner of things including, but not limited to, the visual opacity of the appearance of the body, ${ }^{15}$ but whilst vision may accompany manual listening, it is by no means necessary for the felt immanence of the other's experience in our own. The process is first and foremost an enkinaesthetic intertwining, a circle of the touched and the touching and what comes to light, that is, what is brought forth through the feeling shifting somatic sense. ${ }^{16}$

\footnotetext{
${ }^{13}$ See, for example, William G Sutherland.

${ }^{14}$ For another example of enkinaesthetic intentional transgression of and intertwining within the other's experience see Stuart 2013 "The Union of Two Nervous Systems: Neurophenomenology, Enkinaesthesia, and the Alexander Technique".

${ }^{15}$ The particular historical and cultural treatments of individuals as separable from communities in possession of distinctive souls has also played an important role. See, for example, Benedict's distinction between 'guilt' societies and 'shame' societies. [Benedict 1989]

${ }^{16}$ Another example of the feeling shifting somatic sense and its enkinaesthetic co-articulation is given in Steinbeck's short story The Chysanthemums [Steinbeck 1952] where the protagonist Elisa explains, to a travelling salesman, the sensitive palpating, enquiring and acting, touch of "planting hands".

"Did you ever hear of planting hands?"

"Can't say I have, ma am."

“Well, I can only tell you what it feels like. It's when you're picking off the buds you don't want. Everything goes right down into your fingertips. You watch your fingers work. They do it themselves. You can feel how it is. They pick and pick the buds. They never make a mistake. They're with the plant. Do you see? Your fingers and the plant. You can feel that, right up your arm. They know. They never make a mistake. You can feel it. When you're like that you can't do anything wrong. Do you see that? Can you understand that?"
} 
There is a circle of the touched and the touching, the touched takes hold of the touching; there is a circle of the visible and the seeing, the seeing is not without visible existence; there is even an inscription of the touching in the visible, of the seeing in the tangible - and the converse; there is finally a propagation of these exchanges to all the bodies of the same type and of the same style which I see and touch - and this by virtue of the fundamental fission or segregation of the sentient and the sensible which, laterally, makes the organs of my body communicate and founds transitivity from one body to another." [Merleau-Ponty 1968, p.143]

It is most unfortunate that Merleau-Ponty makes a 'virtue' "of the fundamental fission or segregation of the sentient and the sensible", for it is exactly that which is being contested in manual listening, in focusing, and in the enkinaesthetic co-articulation of meaning which is possible precisely because of our ambiguous transcendence. In the former two cases, osteopathic manual listening and focusing, there must be a development of silence and openness in the psychic life of the practitioner, one in which the continuous chatter and play of words and images must be quieted, and once this quiet is established a felt sense of the other's bodily experience is brought forth. In this somatic awareness to receptivity a conscious, yet still somatic, co-articulation is forming, and "As it forms, the "feel" understands itself" [Gendlin 1997, p.216], it shifts and, with a growing clarity, becomes a referent with a continuously unfolding sense, and so on until another felt shift occurs and the co-articulated meaning alters again. Throughout this process of openness and manual listening the experience of the participants is of a between, neither subject nor object. As an enkinaesthetically co-articulated ambiguous transcendence it is neither one nor other, but instead a prenoetically universal non-individuated being which brings with it the whole fabric of the perceptible world as its twin, the flesh of its flesh.

\section{Conclusion}

So, finally let's return to Mr Venus, who would have been able to surprise and charm Mr Wegg by re-articulating his skeleton, making sense of the individual unintelligible bones in the polyadic microcosms of their numerous intertwinings. We have begun to understand how Mr Venus could articulate this aspect of his world blindfold; his fingers and hands, in their enkinaesthetic enquiry and action, seeking, waiting, and letting come what arises somatically in the manual listening of his habitual trade. He feels for the extension, smoothness, concavity or convexity of the bones, and their somatic feel becomes a semantic felt sense, a felt 'this' which comes without conceptual interruption; as Gendlin would say: their feel understands itself; as I would say: their feel is an enkinaesthetically articulated grasp of a possibility of being. He works not just in the current moment but proceeds feelingly, anticipatingly within horizons of possibilities.

But this is to do with the articulation of bones, and our concern is with the co-articulation of felt meaning as outlined in the ambiguous transcendence of osteopathic manual listening, or in the practice of partnered focusing, or in the reciprocity and community of Leib-Leib enkinaesthetic entanglement. For that kind of affective co-articulation we needed to put feeling and sensing flesh on Mr Wegg's bones. With flesh on his bones he becomes Mr Venus's 'twin' once more and he too can proceed feelingly, trying to understand themselves and articulate their own meanings and values, and each bringing the other, and the whole fabric of their perceptible world, with them too.

\section{Bibliography}

Benedict, R. 1(989) The chrysanthemum and the sword: patterns of Japanese culture, Foreword by Ezra F. Vogel, Houghton Mifflin

Buber, M. (1970) I and thou, translated with prologue and notes by Walter Kaufmann, Edinburgh : T. \& T. Clark 
Carruthers, P. \& Smith, P. K. (eds.) (1996) Theories of theories of mind, Cambridge: Cambridge University Press

Chemero, A. (2006) "Information and direct perception: A new approach", in P. Farias \& J. Queiroz (Eds.), Advanced issues in cognitive science and semiotics, pp. 59-72 Aachen: Shaker Verlag

Davies, M. \& Stone T. (eds.) (1995) Folk Psychology: The Theory of Mind Debate, Oxford: Blackwell Publishers

Dickens, C. (1865) Our Mutual Friend, London: Chapman and Hall

DSM-5 (2013) Diagnostic and statistical manual of mental disorders: DSM-5, American Psychiatric Association, Arlington, Va., London

Gallagher, S. \& Meltzoff, A. (1996) "The earliest sense of self and others: Merleau-Ponty and recent developmental studies”, Philosophical Psychology, 9, pp.211-33

Gallagher, S. \& Marcel, A. J. (1999) "The Self in Contextualized Action”, Journal of Consciousness Studies, 6 (4), pp.4-30

Gallagher, S. (2008) "Direct perception in the intersubjective context",Consciousness and Cognition, 17 (2), pp.535-543

Gendlin, E.T. (1966). "The discovery of felt meaning”, in J.B. McDonald \& R.R. Leeper (Eds.), Language and meaning, Papers from the ASCD Conference, The Curriculum Research Institute (Nov. 21-24, 1964 \& March 20-23, 1965), pp. 45-62. Washington, DC: Association for Supervision and Curriculum Development. From http: //www. focusing.org/gendlin/docs/ gol_2039.html

Gendlin, E. T. (1992) “The primacy of the body, not the primacy of perception”, Man and World', 25 (3-4), pp.341-53

Gendlin, E. T. (1997). A process model. New York: The Focusing Institute. (Also available at http://www.focusing.org/process.html)

Gendlin, E. T. (2015) “A New Way of Thinking-About Anything-and How to Write From It”, Synthesis Philosophica, forthcoming

Husserl, E. (1989) Ideas Pertaining to a Pure Phenomenology and to a Phenomenological Philosophy, Second Book (Ideas II), trans. R. Rojcewicz \& A. Schuwer, Dordrecht: Kluwer

Hutcheson, F. (2005) A system of moral philosophy, in two volumes (1755), Intro. Daniel Carey, London; New York : Continuum

Ingold, T. (2000) The perception of the environment: Essays on livelihood, dwelling and skill, Abingdon, UK: Routledge

Latour, B. (1999) “On Recalling ANT”, The Sociological Review, 47, (S1), 15-25

Latour, B. (2005) Reassembling the Social: An Introduction to Actor-Network-Theory, Oxford: Oxford University Press

Leibniz, F. W. (1991) G. W. Leibniz's Monadology, An Edition for Students, trans. Nicholas Rescher, University of Pittsburgh Press

Macmurray, J. (1961) Persons in Relation, London: Faber \& Faber

Malloch, S. \& Trevarthen, C. (Eds.) (2009) Communicative Musicality, Exploring the Basis of Human Companionship, Oxford: Oxford University Press

Merleau-Ponty, M. (1962) Phenomenology of perception, New York: The Humanities Press. Trans. Colin Smith, London: Routledge and Kegan Paul

Merleau-Ponty, M. (1964a) Signs, Northwestern University Press, Evanston, Illinois 
Merleau-Ponty, M. (1964b) The Primacy of Perception, And Other Essays on Phenomenological Psychology, the Philosophy of Art, History and Politics, trans. James M. Edie, Northwestern University Press, Evanston, Illinois

Merleau-Ponty, M. (1968) The Visible and The Invisible, ed. Claude Lefort, trans. Alphonso Lingis, Northwestern University, Studies in Phenomenology and Existential Philosophy, Evanston, Illinois

Merleau-Ponty, M. (1970) Themes from the Lectures at the Collège de France, 1952-1960, trans. by John O’Neill, Northwestern University Press, Evanston, Illinois

Pollatos, O., Gramann, K., \& Schandry, R. (2007)“Neural systems connecting interoceptive awareness and feelings", Human Brain Mapping January, 28 (1), pp.9-18

Reddy. V. (2008) How Infants Know Minds, Harvard University Press

Gens, J-C. \& Roche, E. (2014) “The emergence of feeling in osteopathic manual listening”, conference presentation, Consciousness and Experiential Psychology Section Conference, Sidney Sussex College, Cambridge, 4-6 September 2014

Shakespeare, W. (1969) King Lear, Penguin Books Ltd., Harmondsworth, Middlesex, London, pp.24894

Smith, A. (1976) The Theory of Moral Sentiments (1759), edited by D.D. Raphael \& A.L. Macfie, Oxford : Clarendon Press

Sperry, R. W. (1939) “Action current study in movement coordination” Journal of General Psychology 20, pp.295-313

Steinbeck, J. (1952) “The Chrysanthemums", in 50 Great Short Stories, edited by Milton Crane, Bantam Classics, Bantam Dell, New York, pp.337-48

Stuart, S. A. J. (2010) "Enkinaesthesia, Biosemiotics and the Ethiosphere", in Signifying Bodies: Biosemiosis, Interaction and Health, The Faculty of Philosophy, University of Braga, Portugal, pp.305-30

Stuart, S. A. J. (2012) "Enkinaesthesia: the essential sensuous background for co-agency", In: Radman, Z. (ed.) The Background: Knowing Without Thinking, Palgrave Macmillan, Chp. 8, pp.167-86

Stuart, S. A. J. (2013) “The Union of Two Nervous Systems: Neurophenomenology, Enkinaesthesia, and the Alexander Technique", Journal of Constructivist Foundations, 8, (3), pp. 314-23

Stuart, S. A. J. \& Thibault, P. J. (2015) "Enkinaesthetic Polyphony as the Underpinning for Firstorder Languaging", Emotion in Language: Theory - Research - Application, edited volume, John Benjamins Publishing (forthcoming)

Sutherland, W. G. at http://www. cranialacademy.com/cranial.html

Trevarthen, C. (2009)“Embodied Human Intersubjectivity: Imaginative Agency, To Share Meaning”, Journal of Cognitive Semiotics, IV (1), pp.6-56

Varela, F., Thompson, E., \& Rosch, E. (1991) The Embodied Mind: Cognitive Science and Human Experience, Cambridge, MA: MIT Press

Willett, C. (2014) Interspecies Ethics, Columbia University Press

Wittgenstein, L. (1958) Philosophical Investgations, Basil Blackwell Ltd., Oxford

Young, I. M. (1980) "Throwing like a Girl: A Phenomenology of Feminine Body Comportment Motility and Spatiality", Human Studies, 3(2) pp.137-56 